\title{
THE RESULTS - LESS SUCCESSFUL/UNEMPLOYED SAMPLE
}

As we have discussed, success is subjective. It might be easier to say what it's not. Are those who are unemployed, struggling in a low paid and unsatisfying jobs successful? This is the subject of the second part of this book, a study of lesser successful or unemployed dyslexics, with the interview of 10 lesser successful/unemployed dyslexics, and 54 from an online study.

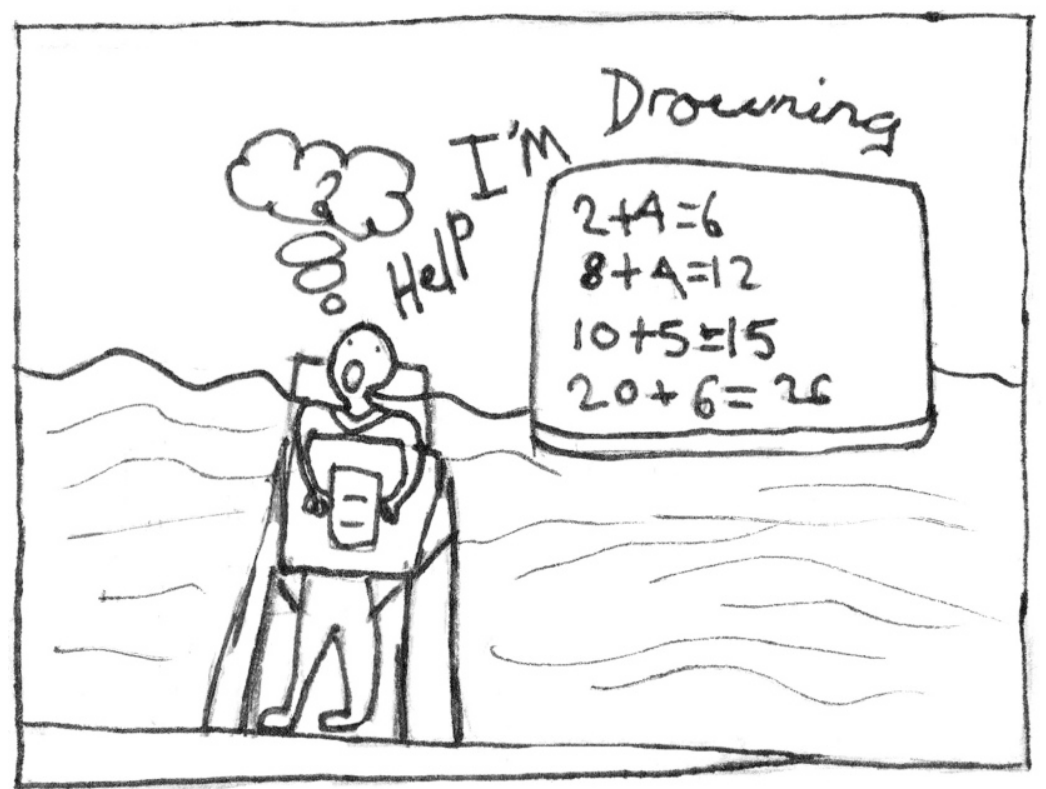

